University of Nebraska - Lincoln

DigitalCommons@University of Nebraska - Lincoln

Faculty Publications from Nebraska Center for Research on Children, Youth, Families, and Schools

$4-6-2020$
Children, Youth, Families \& Schools, Nebraska Center for Research on

\title{
Fathers' perceived co-parenting and children's academic readiness among Chinese preschoolers: Longitudinal pathways through parenting and behavioral regulation
}

\author{
Lixin Ren \\ Rebecca Y.M. Cheung \\ Courtney Boise \\ Xuan Li \\ Jieqiong Fan
}

Follow this and additional works at: https://digitalcommons.unl.edu/cyfsfacpub

Part of the Bilingual, Multilingual, and Multicultural Education Commons, Child Psychology Commons, Counseling Psychology Commons, Developmental Psychology Commons, Early Childhood Education Commons, Educational Psychology Commons, Family, Life Course, and Society Commons, and the Other Social and Behavioral Sciences Commons

This Article is brought to you for free and open access by the Children, Youth, Families \& Schools, Nebraska Center for Research on at DigitalCommons@University of Nebraska - Lincoln. It has been accepted for inclusion in Faculty Publications from Nebraska Center for Research on Children, Youth, Families, and Schools by an authorized administrator of DigitalCommons@University of Nebraska - Lincoln. 


\title{
Fathers' perceived co-parenting and children's academic readiness among Chinese preschoolers: Longitudinal pathways through parenting and behavioral regulation
}

\author{
Lixin Ren, ${ }^{1,2}$ Rebecca Y.M. Cheung, ${ }^{3}$ Courtney Boise, ${ }^{4}$ \\ Xuan Li, 5 \& Jieqiong Fan ${ }^{1,2}$
}

\begin{abstract}
1 East China Normal University, China Quality, China 3 The Education University of Hong Kong, China 4 University of Nebraska-Lincoln, United States 5 New York University Shanghai, China
\end{abstract}

2 Collaborative Innovation Center for Assessment Towards Basic Education

Corresponding author - R.Y.M. Cheung, Department of Early Childhood Education, Centre for Child and Family Science, and Centre for Psychosocial Health, The Education University of Hong Kong, Tai Po, N.T., Hong Kong. Tel.: +852 2948 8853; Email rymcheung@eduhk.hk

\begin{abstract}
Co-parenting quality has frequently been linked to young children's social-emotional functioning, but limited research has focused on the relationship between co-parenting and children's early academic skills, or the underlying mechanisms through which co-parenting influences children's development. Using data collected from urban China, the present study examined how fathers' perceptions of co-parenting quality was related to their preschool-aged children's academic readiness (i.e.,
\end{abstract}

Published in Early Childhood Research Quarterly 53 (2020) 77-85

DOI: 10.1016/j.ecresq.2020.03.005

Copyright (C) 2020 Elsevier Inc. Used by permission.

Submitted 3 May 2019; revised 5 March 2020; accepted 10 March 2020; published 6 April 2020. 
receptive vocabulary, reading, early math; $N=336$ ), and whether father's parenting practices and children's behavioral regulation mediated the link between co-parenting quality and child outcomes. Findings suggested that the relation between co-parenting quality and children's academic readiness was mediated by children's behavioral regulation. However, fathers' parenting practices were not related to children's academic readiness, nor did fathers' parenting practices mediate the relations between co-parenting and child outcomes. The present findings were consistent between boys and girls. That is, the mediating process did not differ as a function of child gender. The study highlights the importance of fostering a quality co-parenting relationship to better support children's development of behavioral regulation and academic readiness.

Keywords: Co-parenting, Academic readiness, Behavioral regulation

According to family systems theory, a family is an organized whole constituted of interrelated subsystems, among which co-parenting is an important subsystem (Cox \& Paley, 1997). Co-parenting, defined as an enterprise "involving the coordination between adults responsible for the care and upbringing of children" (McHale, Kuersten-Hogan, \& Rao, 2004, p. 222), reflects the way parents connect with each other in childrearing (Pedro, Ribeiro, \& Shelton, 2012). Co-parenting includes several components such as cooperation, interparental conflict, and triangulation (Margolin, Gordis, \& John, 2001; Pedro et al., 2012). The quality of co-parenting has been linked to parent-level outcomes, such as mental health (Cabrera, Scott, Fagan, Steward-Streng, \& Chien, 2012) and parental warmth (Bonds \& Gondoli, 2007). The association between co-parenting and children's social-emotional adjustment has also been widely supported (Teubert \& Pinquart, 2010). However, little research has examined the relation between co-parenting and children's preacademic skills (Cabrera et al., 2012), which lay the foundation for their future achievement (Duncan et al., 2007). It is therefore of great value to investigate how familial factors, such as co-parenting, contribute to the development of these early skills.

Despite the growing evidence supporting the associations between co-parenting and child outcomes, little is known about the underlying process of such associations. In this study, we explore two potential mechanisms-parenting practices and children's behavioral regulation-through which co-parenting may relate to child preacademic skills. The existing scholarship also heavily focuses on mothers' perceived co-parenting and its influences on child development, 
although empirical studies suggest that fathers' parenting practices are more sensitive to the quality of couple relationship (Krishnakumar and Buehler, 2000). In this study, we attend to the still understudied contributor of child development by investigating the links among fathers' perceived co-parenting, fathers' parenting practices, and child outcomes. Furthermore, we move beyond the typical focus on WEIRD (Western, Educated, Industrialized, Rich, and Democratic) samples, given that the cultural context of family life may influence family processes (Rogoff, 2003). Chinese fathers, for example, are traditionally considered the children's educators and are expected to complement the mothers' parental role. However, rapid social changes in China, such as the rise of nuclear families and the rising significance of the couple relationship, are redefining the fathers' roles in the family (Jankowiak \& Li, 2014; Li \& Lamb, 2015). The current study thereby aims to further our understanding of the underlying pathways linking co-parenting to children's preacademic development, which will in turn provide practitioners and policy makers with potential ways to support family functioning in the Chinese cultural context.

\section{Co-parenting and child outcomes}

Because co-parenting is essentially a child-focused relationship between two or more caregivers, co-parenting is arguably closer and more salient to children's development than other aspects of the parental relationship, such as marital quality (Bonds \& Gondoli, 2007). The link between co-parenting and children's social-emotional functioning has been confirmed by many empirical studies, although primarily in Western samples. For example, a meta-analysis of 59 studies that involved children younger than 18 years of age found significant associations between several dimensions of co-parenting and diverse child social-emotional outcomes (Teubert \& Pinquart, 2010). In addition, Kwon and Elicker (2012)reported that observed co-parenting quality uniquely contributed to toddlers' social functioning beyond observed general parenting practices displayed during clean-up tasks, suggesting that the coordination between parents in childrearing is of significant value in addition to what either parent does individually. In Chinese samples, McHale, Rao, and Krasnow (2000) reported 
positive associations between mother-reported co-parental conflict and Chinese preschoolers' behavioral problems. A more recent study of Chinese preschool children also found that parent-reported co-parental cooperation was a protective factor for social competence, peer acceptance, and social cognition among children with high negative affect (Lam, Tam, Chung, \& Li, 2018).

Academic readiness constitutes an important developmental domain in children's early years (Duncan et al., 2007). How-ever, existing research on the relations between co-parenting and children's early academic skills remains scarce and inconsistent compared to the relatively robust link between co-parenting and child social-emotional outcomes. For example, Cabrera et al. (2012)found that motherreported co-parental conflict with fathers measured when children were 24 months old had negative effects on children's math and literacy skills assessed at 48 months old, whereas co-parenting communication had positive effects, and shared decision-making was not related to children's early academic skills. In addition, the pathways did not differ between mothers' and fathers' perceptions of co-parenting. In an investigation of Mexican-origin teenage mothers with preschoolaged children living in the United States, Jahromi, Zeiders, Updegraff, Umaña-Taylor, and Bayless (2018) discovered a positive correlation between mother-reported co-parenting communication with the child's biological father and child literacy skills assessed at five years of age, while co-parenting conflict and communication with the child's grandmother as well as co-parenting conflict with the child's biological father were unrelated to child math or literacy competence at five years old. We located only one study pertaining to Chinese preschool-aged children, which asked mothers to report their Academic readiness constitutes an important developmental domain in children's early years (Duncan et al., 2007). How-ever, existing research on the relations between co-parenting and children's early academic skills remains scarce and inconsistent compared to the relatively robust link between co-parenting and child social-emotional outcomes. For example, Cabrera et al. (2012) found that mother-reported co-parental conflict with fathers measured when children were 24 months old had negative effects on children's math and literacy skills assessed at 48 months old, whereas co-parenting communication had positive effects, and shared decision-making was not related to children's 
early academic skills. In addition, the pathways did not differ between mothers' and fathers' perceptions of co-parenting. In an investigation of Mexican-origin teenage mothers with preschool-aged children living in the United States, Jahromi, Zeiders, Updegraff, Umaña-Taylor, and Bayless (2018) discovered a positive correlation between motherreported co-parenting communication with the child's biological father and child literacy skills assessed at five years of age, while coparenting conflict and communication with the child's grandmother as well as co-parenting conflict with the child's biological father were unrelated to child math or literacy competence at five years old. We located only one study pertaining to Chinese preschool-aged children, which asked mothers to report their

\section{The role of parenting as a mediator}

How exactly does co-parenting quality influence child development? Guided by family systems theory (Cox \& Paley, 1997), researchers have proposed and tested parenting quality as a mediator in the relations between co-parenting and child outcomes (Bonds \& Gondoli, 2007; Cabrera et al., 2012; Kwon, Jeon, \& Elicker, 2013). As confirmed by several studies, parents' ability to collabo-rate with and support each other in childrearing can afford them the necessary resources to deliver effective parenting practices (e.g., Bonds \& Gondoli, 2007; Morrill, Hines, Mahmood, \& Córdova, 2010; Pedro et al., 2012). For instance, higher levels of perceived co-parental support/ alliance were found to relate to more self-reported positive parenting in both fathers and mothers (Bonds \&Gondoli, 2007; Morrill et al., 2010). Pedro et al. (2012) examined three aspects of parent-reported co-parenting (i.e., co-parental cooperation, triangulation, conflict) as well as three dimensions of parent-reported parenting practices (i.e., emotion support, rejection, control attempts) among families with at least one child between nine and 13 years old of age. They demonstrated that all three aspects of co-parenting predicted one or more aspects of parenting practices for both mothers and fathers. Similar patterns of linkage between co-parenting quality and parents' child rearing practices were also found in Asian families (McHale, Dinh, \& Rao, 2014). For instance, Chen (2018) reported a positive association between mother-reported supportive co-parenting and maternal 
warmth as well as a negative association between undermining coparenting and maternal warmth among two-child Chinese families in which the younger child was enrolled in preschool at the time of the study. However, to our knowledge, the relations between co-parenting and paternal parenting practices have not been examined in the Chinese culture, thereby leaving a major gap concerned with cultural relevance and applicability.

So far, several existing studies have revealed the pathway linking co-parenting to child social-emotional development via parenting practices (Kwon et al., 2013; Lindsey \& Mize, 2001; O'Leary \& Vidair, 2005; Parkes, Green, \& Mitchell, 2019). For instance, O'Leary and Vidair (2005) found that among families with 3-to-7 years old children, childrearing disagreement indexed by both mothers' and fathers' reports was positively linked to girls' internalizing and externalizing problems via parent self-reported over-reactive parenting; however, child rearing disagreement was only indirectly related to boys' externalizing problems through mothers' over-reactive parenting. Lindsey and Mize (2001) found that observed parental responsiveness during parent-child play interaction partially or fully mediated the link between parent-reported interparental agreement and the social competence in their 3-to-5 years old children, depending on the parent's gender. Kwon et al. (2013) assessed parents 'gentle guidance behavior through observations of parent-child interaction during a cleanup session, and they reported that mothers' gentle guidance, but not fathers' gentle guidance, mediated the association between parentreported co-parenting quality and toddlers' social-emotional competency. Overall, the findings sup-ported the mediating role of parenting in the association between co-parenting and child adjustment across different conceptualizations and measurements of co-parenting, parenting, and child adjustment. These findings also demonstrated that parent gender and child gender were important contextual factors to consider in examining the relations among these constructs.

Cabrera et al. (2012) examined the mediating effect of observed parenting on the association between mother-reported co-parenting and children's academic readiness measured through direct child assessments. Among the three dimensions of co-parenting (i.e., coparenting communication, co-parenting conflict, and shared decision making) included in the study, only parent-reported co-parenting 
communication when the children were 24 months old predicted children's early math and literacy skills at 48 months through maternal supportiveness assessed via a parent-child interaction task. The effects were similar for mother-and father-reported co-parenting. Chen et al. (2017) found among urban Taiwanese families with elementary school children that parent-reported involvement in education was a partial mediator for parent-perceived co-parenting and children's academic success, suggesting that similar patterns of relations among co-parenting, parenting, and child academic development may operate among preschool-aged children in Chinese societies.

\section{The role of self-regulation as a mediator}

Because of its salient impact on children's academic achievement and social behaviors, self-regulation has been identified as an explanatory mechanism that accounts for the relations between family-related factors and child outcomes (e.g., Evans\& Rosenbaum, 2008; Hardaway, Wilson, Shaw, \& Dishion, 2012).An important aspect of selfregulation is behavioral regulation, which refers to a child's ability to apply executive function skills to adaptive behaviors (Sektnan, McClelland, Acock, \& Morrison, 2010). Specifically, behavioral regulation entails key learning-related behaviors, including focusing and maintaining attention on tasks, following directions, and inhibiting inappropriate behaviors (Sektnan et al., 2010). Not surprisingly, behavioral regulation is related to early math, literacy, and reading skills among both Western and Chinese preschoolers (e.g., McClelland et al., 2014; Ren, Zhang, Yang, \& Song, 2018).

Preschoolers' self-regulatory competence can be cultivated in the family sphere (Feinberg, Kan, \& Goslin, 20o9; Karreman, van Tuijl, van Aken, \& Deković, 2008). Recent work, for instance, has highlighted the importance of fathers' contributions to preschoolers' selfregulation and academic readiness (Meuwissen \& Carlson, 2015; Meuwissen \& Carlson, 2018). Positive parenting and co-parenting may help create a less stressful family environment that can influence children's stress-related physiological systems, which can in turn translate into greater capacities to self-regulate(Feinberg et al., 2009). High-quality parenting and co-parenting can also promote children's self-regulation 
development by nurturing secure attachment relationships (Jahromi et al., 2018). Emerging evidence has indeed demonstrated that selfregulation can be a potential mechanism for the relation between parenting (Devine, Bignardi, \& Hughes, 2016) or co-parenting (Jahromi et al., 2018) and children's academic outcomes. For example, Devine et al. (2016)demonstrated that greater observed parental negativity displayed during parent-child play predicted lower levels of child behavioral regulation, which in turn predicted poorer early academic abilities in preschool-aged children. Jahromi et al. (2018) reported that teenage mothers' perceived co-parenting conflict with their child's biological father was indirectly linked to their preschool-aged children's letter/word identification skills through child regulatory control, albeit only for daughters. Thus, behavioral regulation maybe a mechanism that underlies the relations between co-parenting, parenting, and children's academic readiness.

\section{The present study}

The existing studies on co-parenting, parenting practices, and child outcomes have provided much insight about the links between family subsystems and child development, yet the findings regarding the father's role remains scarce and inconclusive. We know even less about such family processes in non-WEIRD societies. This study aims to address these gaps by exploring the underlying processes that might be responsible for the potential indirect influence of fathers' perceived co-parenting on children's academic readiness in a Chinese sample. It was expected that fathers' perceptions of co-parenting would be directly linked to their authoritative and authoritarian parenting practices, which would in turn relate to children's behavioral regulation and subsequently to children's academic readiness. Specifically, we hypothesized that when fathers perceived having better-quality coparenting, they would be more likely to adopt authoritative parenting styles and less likely to employ authoritarian parenting. Higher levels of authoritative parenting and lower levels of authoritarian parenting would be related to better children's behavioral regulation, which would in turn contribute to their academic readiness in the domains of receptive language, reading, and early math. Some studies have revealed that co-parenting can directly impact child adjustment beyond 
parenting practices (e.g., Cabrera et al., 2012). Thus, we hypothesize that co-parenting would also contribute directly to children's behavioral regulation and academic readiness. We also hypothesized direct paths from authoritative and authoritarian parenting to academic readiness, because parenting may also affect child academic readiness through other mechanisms beyond behavioral regulation.

\section{Methods}

\subsection{Participants}

A total of 336 Chinese children and their parents, recruited from 11 preschools in Shanghai, participated in the research. Children were in their final academic year of preschool at the time of the study (mean age at Time $1=67.65$ months, $S D=3.87$ ). Table 1 presents the demographic information of the sample. Two waves of data were collected over a span of seven months. In the fall semester of the academic year (Time 1/T1), children were individually assessed by trained research assistants in terms of their behavioral regulation, and cognitive and language development. The assessment session lasted 30-40 min for each child. A standardized "family socioeconomic status (SES)" variable, which was indexed by the average of the standardized scores of the following five variables: paternal education, maternal education, paternal occupation, maternal occupation, and family income within a given family (see Table 1 for specific levels of each variable), was con-trolled for in further analyses. Parents completed a questionnaire packet that included a demographic survey and inventories assessing their co-parenting and parenting practices. At the end of the following spring semester (Time 2/T2), children's receptive vocabulary, reading, and early math were individually assessed. The assessment was divided into two sessions. The first session assessing children's receptive vocabulary was usually around $15 \mathrm{~min}$ for each child, while the second session assessing children's ability of reading and early math took approximately $20-30 \mathrm{~min}$.

A total of $303(90.18 \%)$ children remained in the study from T1 to T2. Attrition analyses were conducted to compare whether children differed on key study variables between those who dropped out and 
Table 1 Demographic information of the sample.

\begin{tabular}{|c|c|c|}
\hline Variables & $M(S D) \%$ & \\
\hline Child age at Time 2 (month) & $4.48(3.92)$ & \\
\hline Percentage of girls & $53.0 \%$ & \\
\hline Percentage of single children & $72.1 \%$ & \\
\hline \multicolumn{3}{|l|}{ Marital status } \\
\hline Married & $99.1 \%$ & \\
\hline Remarried & $0.9 \%$ & \\
\hline \multicolumn{3}{|l|}{ Family monthly income (scored below from 1 to 6 ) } \\
\hline 1. $8000 \mathrm{RMB}$ and less & $5.2 \%$ & \\
\hline 2. 80 oo1-15 ooo RMB & $18.5 \%$ & \\
\hline 3. 15 Oo1-20 Ooo RMB & $18.2 \%$ & \\
\hline 4. 20 001-50 o0o RMB & $42.6 \%$ & \\
\hline 5. 50 oo1-80 ooo RMB & $10.9 \%$ & \\
\hline 6. 80 ooo RMB and more & $4.6 \%$ & \\
\hline Parental education (scored below from 1 to 4 ) & Mother & Father \\
\hline 1. High school or below & $12.8 \%$ & $13.7 \%$ \\
\hline 2. Associate college degree & $23.1 \%$ & $18.2 \%$ \\
\hline 3. Bachelor's degree & $51.4 \%$ & $44.4 \%$ \\
\hline 4. Master's degree or above & $12.8 \%$ & $23.7 \%$ \\
\hline Parental occupation (scored below from 1 to 5 ) & Mother & Father \\
\hline 1. Unemployed & $15 \cdot 9 \%$ & $4.0 \%$ \\
\hline 2. Non-technical or semi-technical worker, small business owner & $4 \cdot 3 \%$ & $10.0 \%$ \\
\hline 3. Technical worker or semi-professional (e.g., driver) & $42.5 \%$ & $24.6 \%$ \\
\hline 4. Professional or officer (e.g., doctor, teacher, technician) & $33.3 \%$ & $48.9 \%$ \\
\hline 5. High-level professional or administrator (e.g., manager) & $4.0 \%$ & $12.5 \%$ \\
\hline
\end{tabular}

those who stayed in the study. There was no statistically significant difference in child age, child gender, T1 child cognitive and language development, child behavioral regulation, mother-reported authoritarian parenting, or father-reported authoritative parenting ( $p s>.05)$. However, those who remained in the study had higher family SES ( $F=$ 27.37, $p<.001)$, mother-reported authoritative parenting $(F=21.28$, $p<.001)$, father-reported co-parenting $(F=8.07, p=.005)$, and father-reported authoritative parenting $(F=18.00, p<.001)$. We speculate that higher-SES parents were likely to have more time or stronger motive to participate in child development studies compared to relatively lower-SES parents. Family SES has been found to have positive associations with parenting behavior (Conger, Conger, \& Martin, 2010), which helped explain why remaining families tended to have more positive parenting and co-parenting compared to families 
who dropped out. To address the missing data issue to some extent, we controlled for family SES in further analyses. We also controlled for maternal parenting practices to better examine the unique effects of fathering on child outcomes. However, it is worth noting that the results remained similar whether or not we included maternal parenting practices as covariates in the models. In addition, full information maximum likelihood estimation was used in the analyses to handle missing data.

\subsection{Measures}

Fathers' perceived co-parenting at T1. Fathers reported their perceptions of the co-parenting relationship using the Co-parenting Relationship Quality questionnaire (CRQ; Stright \& Bales, 2003) on a 5-point scale ( 1 = never, 5 = always). The CRQ assessed two dimensions of co-parenting: supportive co-parenting (7 items; e.g., "When I tell my partner something about our child, he/she listens") and undermining co-parenting (7 items; e.g., "When I tell our child to do something, my partner contradicts"). As the two dimensions were highly correlated in this study $(\mathrm{r}=-.64, \mathrm{p}<.001)$, the undermining co-parenting items were reversely coded, and all items were then averaged to create an overall index of co-parenting quality. Cronbach's alpha was .90 in this study.

Parenting practices at T1. Fathers' and mothers' parenting practices were measured using the short-form Parenting Styles and Dimensions Questionnaire (PSDQ; Wu et al., 2002). Fathers and mothers were instructed to complete the questionnaire on their own. The 15-item Authoritative Parenting subscale captures parental warmth and sensitivity, the use of reasoning and induction, and autonomy granting. The 11-item Authoritarian Parenting subscale describes parents' use of physical coercion, verbal hostility, and non-reasoning. The PSDQ includes five response options ( $1=$ never, $5=$ always $)$. In this study, Cronbach's alphas were .89 (mother)/.91(father) and .85 (mother)/.84 (father) for the Authoritative and Authoritarian subscales, respectively.

Behavioral regulation at T1. The Head-Toe-Knees-Shoulders task (HTKS; McClelland et al., 2014) was used to assess children's behavioral regulation. This task consists of three parts with 10 trials in each. 
The first part requires children to do the opposite of two commands, i.e., when they hear the command "touch your head," they should touch their toes, and vice versa. The second part includes an additional two commands ("touch your knees" and "touch your shoulder"). The third part also includes the four commands but the rules are different. The tester used a three-point scale to record children's responses ( $\mathrm{o}=$ incorrect, 1 = self-correct, 2 = correct $)$. The task stopped if the child obtained less than 4 points in any part. The HTKS has been used in Chinese culture and has demonstrated strong psychometric properties (Ren et al., 2018; Zhang, Hu, Ren, \& Fan, 2017). The Cronbach's alpha was .91 in this study.

Cognitive and language development at T1. We controlled for children's cognitive and language development at T1. The East Asia Pacific Early Child Development Scale (EAP-ECDS; Rao et al., 2014) was used to assess children's T1 development. The EAP-ECDS, designed for children in East Asia and the Pacific regions, is an individually administered direct assessment for evaluating children's holistic development. The inventory has been validated in six countries, including China. This study used the Cognitive Development (27 items) subscale and the Language and Emergent Literacy (22 items) subscale of the short-form EAP-ECDS. The Cronbach's alphas were .77 and .69 for the two aforementioned subscales, respectively.

Receptive language at T2. Receptive vocabulary was measured by a Chinese version of the Peabody Picture Vocabulary Test-R (PPVTR, Dunn \& Dunn, 1981), which has been adapted and validated by Lu and Liu (2005) in the Chinese context. The test includes 125 items. For each item, four pictures are displayed on a single page and children are asked to point to the picture that corresponds to the word said by the tester. The test was terminated if children provided incorrect responses for six items in eight consecutive items. The total number of correct answers was used as the final score. The Cronbach's alpha was .95 in this study.

Chinese reading at T2. The Chinese Character Recognition Task (Shu, Peng, \& McBride-Chang, 2008) was used to assess children's Chinese reading skills. In this task, children were presented with a list of 150 Chinese characters and were asked to read them one by one from the beginning. The task stopped when the child failed to read 15 consecutive characters. The total number of correctly read characters 
was used to determine the child's reading score. The reliability and validity of this task has been supported by previous research (e.g., Lei et al., 2011; Zhang et al., 2017). In this study, the Cronbach's alpha was .98.

Early math at T2. Children's early math skills were assessed via the Applied Problems scale, the Calculation scale, and the Math Facts Fluency scale of the Woodcock-Johnson Tests of Achievement (Woodcock, McGrew, \& Mather, 2001). The Applied Problems scale includes 56 items. Testing was stopped if the child failed to answer five consecutive items correctly. The Calculation scale includes 30 items. Testing was stopped if the child failed to answer six consecutive items correctly. The Math Facts Fluency scale includes 16o items. Children were required to answer as many items as possible within 3 min. The raw sum scores of correctly responded items were used in the analyses. The Cronbach's alpha was .97 for all three scales combined.

\subsection{Data analysis}

We presented the hypothesized model in Figure 1. Specifically, T1 fathers' perceptions of co-parenting quality were entered as concurrent predictors of fathers' authoritative and authoritarian parenting practices at T1. T1 co-parenting and parenting variables were entered as concurrent predictors of children's behavioral regulation at T1. All variables were then entered to predict children's academic readiness

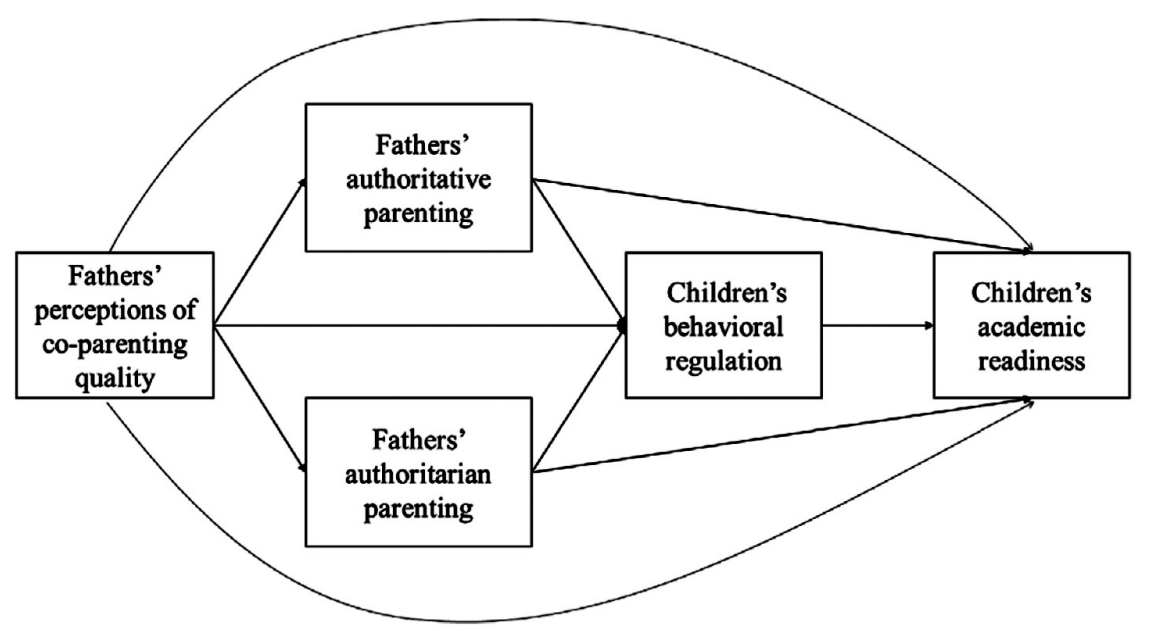

Figure 1. Hypothesized model of parenting practices and child behavioral regulation as mediators between co-parenting and child academic readiness. 
assessed at T2, including receptive language, Chinese reading skills, and early math skills. Children's age and family SES were added as control variables (i.e., adding the paths from children's age and family SES to all variables). We also controlled for T1 children's cognitive development, T1 language and emergent literacy, and maternal parenting practices in predicting the three academic readiness outcomes. Previous research has demonstrated that children's general cognitive and language abilities are domain-general skills that can greatly affect their development of reading and math skills (Passolunghi, Mammarella, \& Altoè, 2008; Zhang et al., 2017). Mothers' parenting practices were also found to predict children's academic readiness (Cabrera et al., 2012). By controlling for these variables, we could reduce potential biases and better examine the effects of father-perceived coparenting on children's academic readiness.

We first conducted a single-group path analysis to test the hypothesized model via Mplus Version 7 (Muthén \& Muthén, 1998-2012). To investigate whether the model could be applied to both genders, we conducted separate single-group analyses for girls and boys, respectively. A multi-group path analysis was further conducted to examine gender as a moderator. The multi-group analysis involved three steps. In the first step, all parameters were freely estimated between genders. In the second step, each pathway compared between boys and girls. When there was no significant difference for a corresponding path between boys and girls ( $p>.05)$, the path could be constrained to be invariant. In the third step, we verified the findings from the second step and constrained the paths to be invariant between boys and girls. We further com-pared between the fit indices of the constrained and unconstrained model. A non-significant $\chi^{2}$ difference between the models would indicate that the simpler model (i.e., the one with constrained paths) should be selected due to the principle of parsimony. Full information maximum likelihood estimation was used to examine the model fit and handle missing data. Bootstrapping was used to evaluate the mediation effects, as previous research suggested that bootstrapping yields more accurate estimates of the indirect effect standard errors than other approaches (Shrout \& Bolger, 2002). 


\section{Results}

Table 2 presents the correlations and descriptive statistics for all variables. Fathers' perception of co-parenting quality was positively correlated with both mothers' and fathers' authoritative parenting and negatively correlated with authoritarian parenting. Father-perceived co-parenting quality was concurrently related to children's behavioral regulation. Unexpectedly, fathers' perception of co-parenting quality was not significantly correlated with any of the academic readiness outcomes at $\mathrm{T} 2$, nor were father-reported parenting practices correlated with any child outcome at either time points, ps $>.05$.

In the single-group analysis involving all data, the model yielded good fit to the data, $\chi^{2}(22)=25.83, p=.26, \mathrm{CFI}=.99$, RMSEA $=.03$, $\mathrm{SRMR}=.03$. In the follow-up single-group analysis involving girls only, the model yielded adequate fit, $\mathrm{X}^{2}(11)=19.49, p=.05$, CFI = .97 , RMSEA $=.07$, SRMR $=.03$. Likewise, the model involving boys only yielded good fit, $\chi^{2}(11)=6.37, p=.85$, CFI $=1.00$, RMSEA = .00, SRMR $=.03$. Subsequent multi-group path analysis that allowed all paths to differ between genders also yielded good fit to the data, $\chi^{2}(22)=24.09, p=.34, \mathrm{CFI}=1.00, \mathrm{RMSEA}=.02$, SRMR $=.03$. Next, we compared each path in the model between boys and girls using the "model constraint" command in M plus. Comparison of the coefficients of each path between boys and girls yielded non-significant results ( $p s>.05$ ), thereby suggesting that a simpler, constrained model between genders should be used. The constrained model between genders fit well to the data, $\chi^{2}(65)=66.01, p=.44$, CFI = $1.00, \mathrm{RMSEA}=.01, \mathrm{SRMR}=.06$. To verify that the constrained model between genders should be selected, we compared the constrained model with the unconstrained model using nested model comparison. The non-significant $\chi^{2}$ difference test between the constrained and unconstrained models converged with the previous step to demonstrate invariance between boys and girls, $\Delta \chi^{2}(43)=41.92, p=.52$. Therefore, the constrained model was retained as our final model, i.e., the associations found in the model were not moderated by child gender. The final model accounted for $4.7 \%$ and $5.5 \%$ of variance in girls' and boys' behavioral regulation, $15.6 \%$ and $19.4 \%$ in girls' and boys' receptive language, $24.8 \%$ and $18.9 \%$ in girls' and boys' 


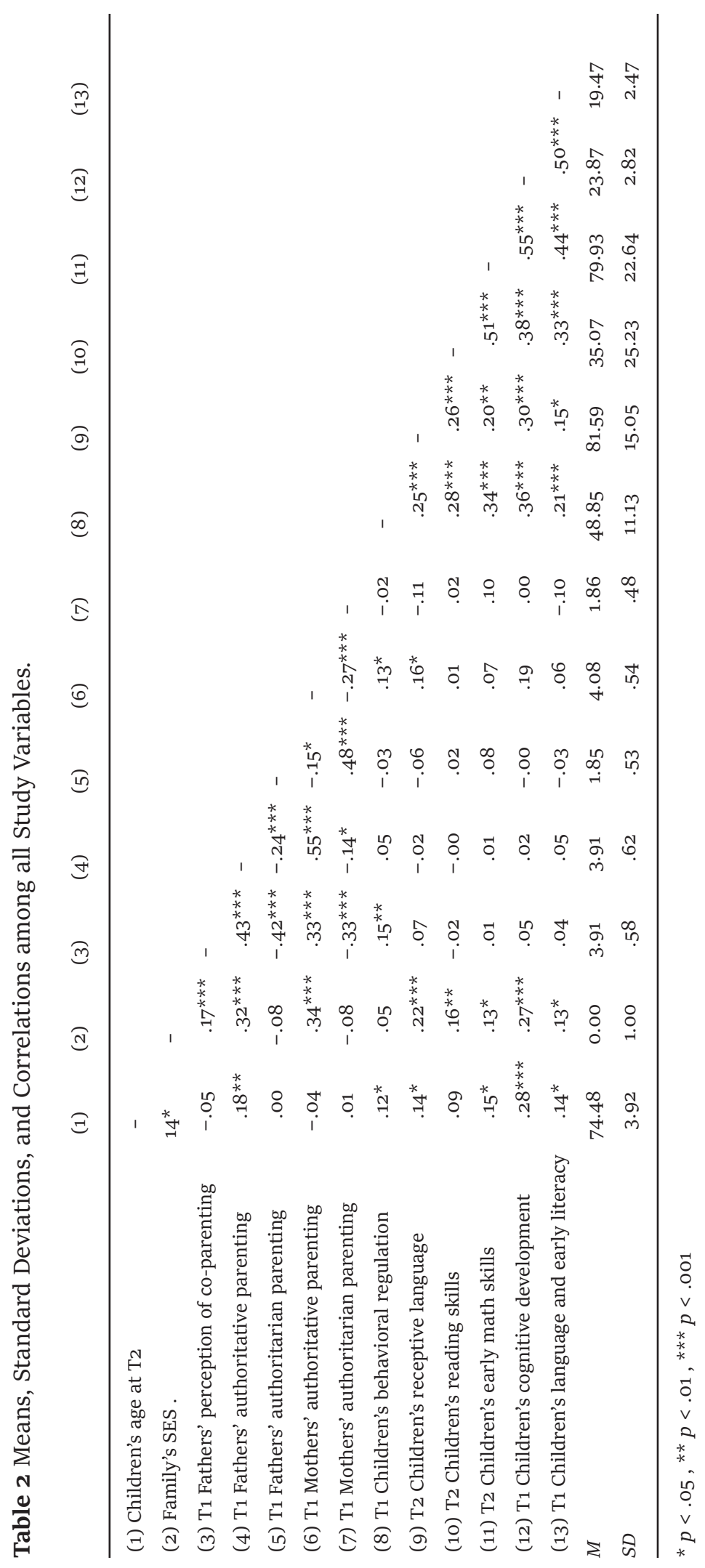


reading skills, and $40.9 \%$ and $36.7 \%$ in girls and boys' math skills, respectively. In Table 3, both the standardized and unstandardized coefficients of the final model were presented. As shown in Figure 2, fathers' perceptions of better co-parenting quality at $\mathrm{T} 1$ was related to higher levels of father-reported authoritative parenting, lower levels of authoritarian parenting, and better child behavioral regulation at T1. However, fathers' authoritative parenting and authoritarian parenting were not significantly related to children's behavioral regulation. Children's behavioral regulation was positively related to their receptive language, reading, and early math skills at $\mathrm{T} 2$.

As for the control variables (see Table 3), children's cognitive development assessed at $\mathrm{T} 1$ positively predicted their reading skills, early math skills, and receptive language at T2. Children's language and emergent literacy at $\mathrm{T} 1$ also positively predicted their subsequent reading and early math skills, but not receptive language. Children's age was negatively related to fathers' authoritative parenting, and it was positively associated with children's behavioral regulation, but it was not significantly related to other variables. Maternal authoritative parenting at T1 did not predict children's receptive language, reading skills, or early math skills at T2. Maternal authoritarian parenting at T1 positively predicted children's later early math skills, but it was unrelated to child receptive language or reading skills. Higher levels of family SES were related to better co-parenting quality perceived by fathers, higher levels of father-reported authoritative parenting, as well as better child receptive language.

Indirect effects were tested via bootstrapping based on 1000 bootstrap samples with replacement. The $95 \%$ confidence intervals(CIs) of the unstandardized indirect effects via children's behavioral regulation between fathers' perceptions of co-parenting quality and children's receptive language [CI: $(.23,1.96)]$, reading skills[CI: $(.63,3.20)]$, and early mathematic skills [CI: $(.49,2.43)]$ did not include zeros. Therefore, child behavioral regulation had significant mediation effects on the relations between father-perceived co-parenting quality and children's academic readiness outcomes. Also, fathers' perceptions of co-parenting quality were not related to children's academic readiness after accounting for the mediating role of behavioral regulation (see Table 3 for the standardized and unstandardized coefficients). The 95\% CIs of the indirect effects between fathers' perceptions of 
Table 3 Unstandardized and standardized estimates of the paths in the final model presented in Figure 2 (unstandardized path coefficients were constrained between boys and girls).

$$
\begin{array}{rr}
\text { Constrained } & \text { Standardized } \beta \\
\text { unstandardized } B(S D s) & \text { Girls/Boys }
\end{array}
$$

Path parameters: core predictors and outcomes

T1 Fathers' perceptions of co-parenting quality

$\rightarrow$ T1 Fathers' authoritative parenting

$\rightarrow$ T1 Fathers' authoritarian parenting

$\rightarrow$ T1 Children's behavioral regulation

$\rightarrow$ T2 Children's receptive language

$\rightarrow$ T2 Children's reading skills

$\rightarrow$ T2 Children's early math skills

T1 Fathers' authoritative parenting

$\rightarrow$ T1 Children's behavioral regulation

$\rightarrow$ T2 Children's receptive language

$\rightarrow$ T2 Children's reading skills

$\rightarrow$ T2 Children's early math skills

T1 Fathers' authoritarian parenting

$\rightarrow$ T1 Children's behavioral regulation

$\rightarrow$ T2 Children's receptive language

$\rightarrow$ T2 Children's reading skills

$\rightarrow$ T2 Children's early math skills

T1 Children's behavioral regulation

$\rightarrow$ T2 Children's receptive language

$\rightarrow$ T2 Children's reading skills

$\rightarrow$ T2 Children's early math skills

Path parameters: control variables and covariates

T1 Children's cognitive development

$\rightarrow$ T2 Children's receptive language

$\rightarrow$ T2 Children's reading skills

$\rightarrow$ T2 Children's early math skills

T1 Children's language and emergent literacy

$\rightarrow$ T2 Children's receptive language

$\rightarrow$ T2 Children's reading skills

$\rightarrow$ T2 Children's early math skills

T1 Mothers' authoritative parenting

$\rightarrow$ T2 Children's receptive language

$\rightarrow$ T2 Children's reading skills

$\rightarrow$ T2 Children's early math skills

T1 Mothers' authoritarian parenting

$\rightarrow$ T2 Children's receptive language

$\rightarrow$ T2 Children's reading skills

$\rightarrow$ T2 Children's early math skills

$\begin{array}{rrr}.40(.06) & .41 / .35 & <.001 \\ -.38(.05) & -.45 /-.39 & <.001 \\ 4.02(1.13) & .21 / .22 & <.001 \\ .47(2.15) & .02 / .02 & .83 \\ -4.05(3.03) & -.10 /-.09 & .18 \\ -1.42(2.38) & -.04 /-.04 & .55 \\ -1.98(1.06) & -.10 /-.12 & .06 \\ -2.74(1.71) & -.11 /-.12 & .11 \\ .29(3.91) & .01 / .01 & .94 \\ -.09(2.44) & -.00 /-.00 & .97 \\ & & .17 \\ 1.65(1.20) & .07 / .09 & .43 \\ -1.60(2.01) & -.05 /-.06 & .52 \\ -1.94(2.99) & -.04 /-.04 & .93 \\ -.20(2.35) & -.01 /-.01 & \\ .21(.07) & .003 \\ .41(.11) & .20 / .16 & <.001 \\ .32(.10) & .17 / 14 & .002\end{array}$

$.73(.37)$

$1.58(.53)$

$2.65(.43)$

$.14 / .14$

$.20 / .16$

.05

$.36 / .32$

.003

$<.001$

$.16(.41)$

$.02 / .03$

$.22 / .21$

.70

2.15 (.59)

$.28 / .29$

$<.001$

2.55 (.43)

$<.001$

2.87 (2.00)

$.09 / .12$

.15

-1.37 (3.58)

$-.03 /-.03$

$.08 / .08$

.70

3.24 (2.62)

$-.05 /-.06$

$.02 / .02$

.48

-1.65 (2.33)

1.16 (3.57)

$.11 / .11$

4.96 (2.36)

.75

.04 
Table 3 (continued)

Constrained Standardized $\beta$

unstandardized $B(S D s) \quad$ Girls/Boys

Children's age

$\rightarrow$ T1 Fathers' perceptions of co-parenting quality

$\begin{array}{rrr}-.01(.01) & -.05 /-.04 & .42 \\ -.02(.01) & -.15 /-.11 & .004 \\ .00(.01) & .00 / .00 & .98 \\ .33(.13) & .12 / .11 & .01 \\ .37(.23) & .11 / .09 & .11 \\ .09(.38) & .02 / .01 & .80 \\ .12(.24) & .02 / .02 & .62\end{array}$

$\rightarrow$ T1 Fathers' authoritative parenting

$\rightarrow$ T1 Fathers' authoritarian parenting

$\rightarrow$ T1 Children's behavioral regulation

$10(.03)$

$.15 / .18$

.004

$\rightarrow$ T1 Fathers' perceptions of co-parenting quality

$\begin{array}{rrr}.10(.03) & .15 / .18 & .004 \\ .15(.03) & .24 / .25 & <.001 \\ -.00(.03) & -.00 /-.00 & .96 \\ .84(.69) & .07 / .09 & .22 \\ 3.04(.90) & .19 / .22 & .001 \\ 2.22(1.45) & .09 / .09 & .13 \\ -.23(1.18) & -.01 /-.01 & .85\end{array}$

$\rightarrow$ Fathers' authoritative parenting

$\rightarrow$ T1 Fathers' authoritarian parenting

$\rightarrow$ T1 Children's behavioral regulation

$\rightarrow$ T2 Children's receptive language

$\rightarrow$ T2 Children's reading skills

$\rightarrow$ T2 Children's early math skills

$-.23(1.18)$

$-.01 /-.01$

.85

Significant parameters are bolded for clarity.

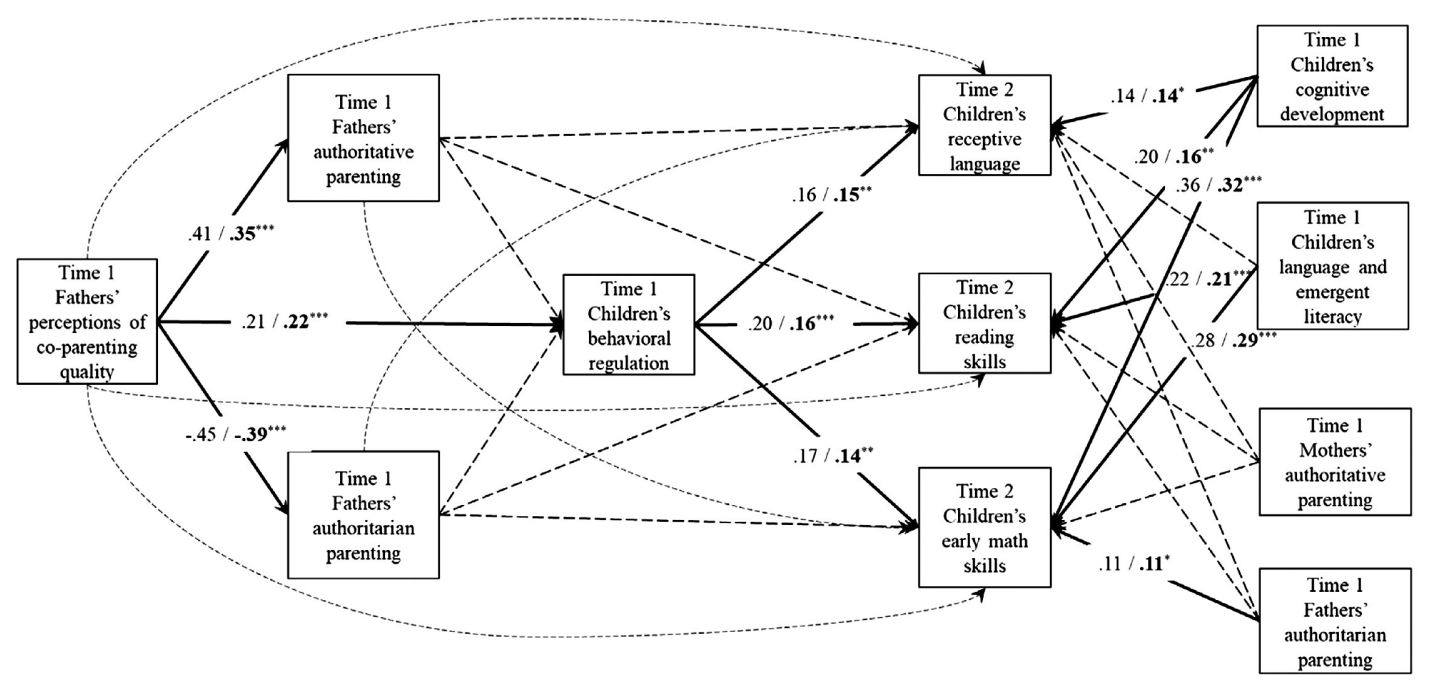

Figure 2. Final model of behavioral regulation as a mediator between co-parenting and academic readiness, $\chi^{2}(65)=66.01, p=.44, \mathrm{CFI}=1.00, \mathrm{RMSEA}=.01$, SRMR $=.06$. Child age and family SES were included as control variables but are not included in the figure for clarity. Unstandardized coefficients were constrained between boys and girls. Standardized coefficients are shown in plain for girls and bold for boys. ${ }^{*} p<.05,{ }^{* *} p<.01,{ }^{* *} p<.001$. 
co-parenting quality and children's academic readiness via fathers' parenting practices included zeros, thereby suggesting fathers' parenting practices were not significant mediators.

\section{Discussion}

Guided by the family systems framework (Cox \& Paley, 1997), the current study examined the link between Chinese fathers 'perceptions of co-parenting quality and their preschool-aged children's academic readiness via fathers' parenting practices and children's behavioral regulation. The findings revealed children's behavioral regulation to be a meaningful mechanism underlying the role of co-parenting in children's receptive vocabulary, Chinese reading, and early math skills. However, fathers' parenting practices did not mediate the relations between fathers 'perceived co-parenting and children's academic readiness, nor did they directly link to any child outcome. All findings were consistent for boys and girls.

\subsection{The mediating role of children's behavioral regulation}

The relations between co-parenting and child academic readiness (i.e., receptive vocabulary, Chinese reading, and early math) were fully mediated by children's behavioral regulation. Our findings supported the connections between co-parenting quality and children's early academic skills, thereby enriching the findings from previous studies that were primarily based on mothers' co-parenting and parenting practices and focused on children's social-emotional adjustment (Cabrera et al., 2012; Teubert \&Pinquart, 2010).

The direct relation between fathers' perceptions of co-parenting quality and children's behavioral regulation suggests the positive role of co-parenting in promoting children's self-regulatory capacities. As the co-parenting relationship can be considered a particular source of social support (Feinberg, 2003), higher levels of father-reported co-parenting quality may indicate greater support from partners. As a result, co-parental support may trans-late into warmer, more relaxed family climate, which can benefit children's stressrelated physiological systems, enabling healthy development of 
self-regulation (Feinberg et al., 2009; Feinberg \&Kan, 2008). Given that the fathers in our sample scored high on authoritative parenting and low on authoritarian parenting, it is also possible that fathers' physical and stimulating interactive style with young children (John, Halliburton, \& Humphrey, 2013) "pro-vide[s] an ideal context in which children may practice and develop their self-regulatory skills, especially when coupled with sensitive and warm paternal behaviors" (Jahromi et al., 2018, p. 472).

It is noteworthy that behavioral regulation had significant predictive power for all three indicators of academic readiness, net of sociodemographic controls, maternal parenting practices, and children's initial cognitive and language development. The findings corroborate the growing evidence on the positive associations between behavioral regulation assessed using the HTKS task and early academic development in Chinese children (Ren et al., 2018; Zhang et al., 2017). Children with better behavioral regulation are more likely to display positive learning behaviors, such as remaining on tasks, which can better enable them to reap the benefits from learning activities in the classroom and at home. In addition, behavioral regulation was found to be associated with children's social-emotional development in previous research (Ren et al., 2018). Children who can better regulate their behaviors may be more apt to build quality relationships with parents, teachers, and peers (Jahromi et al., 2018) to further benefit their learning. This may be particularly true for Chinese preschools characterized by large class sizes and high student-teacher ratios.

\subsection{The lack of effects of parenting practices}

Previous research suggested that co-parenting plays an important role in an array of parental outcomes, such as parental mental health (Cabrera et al., 2012), marital relationship (Feinberg et al., 2009), parenting stress (Margolin et al., 2001), and parenting practices (Lindsey \& Mize, 2001; Pedro et al., 2012). Studies also demonstrated the role of parenting practices in mediating the effects of co-parenting on child outcomes (Kwon et al., 2013; Parkes et al., 2019). For example, fathers' perceptions of co-parenting quality may generate positive feelings and beliefs in themselves, which can spill over to their parenting of children (Feinberg et al., 2009). 
Unlike the previous studies, our study failed to find the expected main or mediation effects of parenting practices on child out-comes. It is worth noting that even without controlling for maternal parenting practices, fathers' parenting practices did not have significant effects on child academic readiness outcomes, therefore excluding the potential explanation that maternal parenting was so strong in predicting child outcomes that the effects of paternal parenting were obscured. We speculate that the lack of effects of fathers' parenting practices may be attributed to our use of parents' self-reports of broad parenting practices, whereas many of the previous studies with significant findings used direct observations or measures of specific parenting behaviors (Cabrera et al., 2012; Cheung, Boise, Cummings, \& Davies, 2018; Kwon et al., 2013; O’Leary \& Vidair, 2005; Parkes et al., 2019). Fathers and mothers in our study might have overrated positive parenting behaviors and underrated negative behaviors due to social desirability. It is also possible that fathers reported their ideal parenting practices to some extent instead of their actual practices, which are yet to be consolidated in actuality to align with their beliefs (Ren \& Edwards, 2016). Future research needs to use direct observations and focus on specific dimensions of parenting in order to better delineate how Chinese paternal parenting is related to co-parenting and child development.

\subsection{Limitations and future directions}

Despite the novel contributions of this study, it is important to note its limitations. First, this study was centered on supportive and undermining co-parenting. Future research is needed to examine whether similar pathways of influence applied to other co-parenting dimensions such as conflict and triangulation. Second, direct observations of parenting practices should be used in future studies to address the limitations of solely relying on parents 'self-reports. Third, it is common in China for grandparents to pro-vide live-in or intensive care for preschool children. Childrearing is thus not simply a joint project between mothers and fathers, but also involves coordination between parents and grandparents. Co-parenting between parents and grandparents should be included in future research to capture the complex dynamics involving multiple agents. Finally, causal conclusions cannot be drawn without experimental designs. In particular, co-parenting 
and child behavioral regulation were assessed at the same measurement occasion. Although we assumed a unidirectional effect of co-parenting on child behavioral regulation based on existing studies (Jahromi et al., 2018; Karreman et al., 2008), bidirectional associations between the two are also likely. Children are active agents in shaping their socialization environments, and children's different characteristics, such as differences in temperamental traits, can evoke different kinds of responses from their parents (Klein et al., 2018). Children with better behavioral regulation may be easier to parent, there-fore eliciting limited disagreement around co-parenting. Future research should explore this potential bidirectional relationship using a cross-lagged panel design. In addition, intervention studies that target co-parenting are needed to explore whether the pathways from co-parenting to children's academic readiness via children's behavioral regulation are causal.

\section{Conclusions and implications}

This study contributes to our knowledge of how fathers' perceptions of co-parenting quality are linked to children's early academic skills. The findings point to the importance of promoting supportive relationships between parents in caring for children. Interventions that simultaneously target the co-parenting relationship and pro-vide parents with strategies to foster children's self-regulation maybe particularly effective in enhancing children's development of vocabulary knowledge, as well as early reading and math. Family Foundations designed by Feinberg et al. (2009) is a program of this type, and it was found to be effective in improving several parent and child outcomes, including co-parenting and child self-regulatory behaviors. This program may be adapted to the Chinese culture. As the current study demonstrated the importance of fathers' perceptions of co-parenting quality, adaptations may include an emphasis on how to promote high-quality paternal involvement in childrearing. Despite the increased paternal involvement in childcare, Chinese fathers' involvement is still much lower than that of mothers ( $\mathrm{Li} \&$ Lamb, 2015). Activating the father's role in childrearing through high-quality co-parenting may greatly contribute to family functioning and children's academic readiness. 
Funding This work was supported by the Humanities and Social Sciences Research Project of the Chinese Ministry of Education (No. 17YJCZH141; No. 18YJCH027); and the Fundamental Research Funds for the Central Universities (No. 2017ECNU-HLYTOO2).

Conflict of interest The authors declare that they have no conflict of interest.

Author contributions Lixin Ren: Conceptualization, methodology, writing - original draft preparation. Writing - review and editing, data curation, resources, funding acquisition. Rebecca Y. M. Cheung: Formal analysis, writing - original draft preparation. Writing - review and editing. Courtney Boise: Writing - original draft preparation. Writing - review and editing. Xuan Li: Writing - original draft preparation. Writing - review and editing. Jieqiong Fan: Writing- original draft preparation. Writing - review and editing.

\section{References}

Bonds, D. D., \& Gondoli, D. M. (2007). Examining the process by which marital adjustment affects maternal warmth: The role of coparenting support as a mediator. Journal of Family Psychology, 21(2), 288-296.

Cabrera, N. J., Scott, M., Fagan, J., Steward-Streng, N., \& Chien, N. (2012). Coparenting and children's school readiness: A mediational model. Family Process, 51(3), 307-324.

Chen, B.-B. (2018). The relationship between Chinese mothers' parenting stress and sibling relationships: A moderated mediation model of maternal warmth and co-parenting. Early Child Development and Care, 1-9.

Chen, H. H., Liang, Y. C., Gapp, S. C., Newland, L. A., Giger, J. T., \& Lin, C. Y. (2017).Direct and indirect links between the couple relationship and child school outcomes. Journal of Experimental Education, 85(4), 658-673.

Cheung, R. Y. M., Boise, C., Cummings, E. M., \& Davies, P. T. (2018). Mothers' and fathers' roles in child adjustment: Parenting practices and mothers' emotion socialization as predictors. Journal of Child and Family Studies, 27(12), 4033-4043.

Conger, R. D., Conger, K. J., \& Martin, M. J. (2010). Socioeconomic status, family processes, and individual development. Journal of Marriage and Family, 72(3),685-704.

Cox, M. J., \& Paley, B. (1997). Families as systems. Annual Review of Psychology, 48(1), 243-267.

Devine, R. T., Bignardi, G., \& Hughes, C. (2016). Executive function mediates the relations between parental behaviors and children's early academic ability. Frontiers in Psychology, 7, 1902.

Duncan, G. J., Dowsett, C. J., Claessens, A., Magnuson, K., Huston, A. C., Klebanov, P., ... \& Japel, C. (2007). School readiness and later achievement. Developmental Psychology, 43(6), 1428-1446. 
Dunn, L. M., \& Dunn, L. M. (1981). Manual for the Peabody Picture Vocabulary Test-Revised. Circle Pines, MN: American Guidance Service.

Evans, G. W., \& Rosenbaum, J. (2008). Self-regulation and the incomeachievement gap. Early Childhood Research Quarterly, 23(4), 504-514.

Feinberg, M. E. (2003). The internal structure and ecological context of coparenting: A framework for research and intervention. Parenting: Science and Practice, 3(2), 95-131.

Feinberg, M. E., \& Kan, M. L. (2008). Establishing family foundations: Intervention effects on coparenting, parent/infant well-being, and parent-child relations. Journal of Family Psychology, 22, 253-263.

Feinberg, M. E., Kan, M. L., \& Goslin, M. C. (2009). Enhancing coparenting, parenting, and child self-regulation: Effects of family foundations 1-year afterbirth. Prevention Science, 10(3), 276-285.

Hardaway, C. R., Wilson, M. N., Shaw, D. S., \& Dishion, T. J. (2012). Family functioning and externalizing behaviour among low-income children: Selfregulation as a mediator. Infant and Child Development, 21(1), 67-84.

Jahromi, L. B., Zeiders, K. H., Updegraff, K. A., Umaña-Taylor, A. J., \& Bayless, S. D. (2018). Coparenting conflict and academic readiness in children of teen mothers: Effortful control as a mediator. Family Process, 57(2), 462-476.

Jankowiak, W., \& Li, X. (2014). The decline of the chauvinistic model of Chinese masculinity: A research report. Chinese Sociological Review, 46(4), 3-18.

John, A., Halliburton, A., \& Humphrey, J. (2013). Child-mother and child-father play interaction patterns with preschoolers. Early Child Development and Care, 183(3-4), 483-497.

Karreman, A., van Tuijl, C., van Aken, M. A. G., \& Deković, M. (2008). Parenting, coparenting, and effortful control in preschoolers. Journal of Family Psychology, 22(1), 30-40.

Klein, M. R., Lengua, L. J., Thompson, S. F., Moran, L., Ruberry, E. J., Kiff, C., \& Zalewski, M. (2018). Bidirectional relations between temperament and parenting predicting preschool-age children's adjustment. Journal of Clinical Child \& Adolescent Psychology, 47(Suppl. 1), S113-S126.

Krishnakumar, A., \& Buehler, C. (2000). Interparental conflict and parenting behaviors: A meta-analytic review. Family Relations, 49(1), 25-44.

Kwon, K. A., \& Elicker, J. G. (2012). The role of mothers' and fathers' parental control and coparenting in toddlers' compliance. Early Education and Development, 23(5), 748-765.

Kwon, K. A., Jeon, H. J., \& Elicker, J. (2013). Links among coparenting quality, parental gentle guidance, and toddlers' social emotional competencies: Testing direct, mediational, and moderational models. Journal of Family Studies, 19(1),19-34.

Lam, C. B., Tam, C. Y. S., Chung, K. K. H., \& Li, X. (2018). The link between coparenting cooperation and child social competence: The moderating role of child negative affect. Journal of Family Psychology, 32(5), 692-698. 
Lei, L., Pan, J., Liu, H., McBride-Chang, C., Li, H., Zhang, Y., . . \& S Shu, H. (2011). Developmental trajectories of reading development and impairment from ages 3 to 8 years in Chinese children. Journal of Child Psychology and Psychiatry, 52,212-220.

Li, X., \& Lamb, M. E. (2015). Fathering in Chinese culture: Traditions and transitions. In J. L. Roopnarine (Ed.), Fathers across cultures: The importance, roles, and diverse practices of dads (pp. 273-306). Santa Barbara, CA, US: Praeger/ABC-CLIO.

Lindsey, E. W., \& Mize, J. (2001). Interparental agreement, parent-child responsiveness, and children's peer competence. Family Relations, 50, 348-354.

Lu, L., \& Liu, H. (2005). Peabody picture vocabulary test-revised manual. Taipei, Taiwan: Psychological Publishing.

Margolin, G., Gordis, E. B., \& John, R. S. (2001). Coparenting: A link between marital conflict and parenting in two-parent families. Journal of Family Psychology, 15(1), 3-21.

Meuwissen, A. S., \& Carlson, S. M. (2015). Fathers matter: The role of father parenting in preschoolers' executive function development. Journal of Experimental Child Psychology, 140, 1-15.

Meuwissen, A. S., \& Carlson, S. M. (2018). The role of father parenting in children's school readiness: A longitudinal follow-up. Journal of Family Psychology, 32(5), 588-598.

McClelland, M. M., Cameron, C. E., Duncan, R., Bowles, R. P., Acock, A. C., Miao, A., \& Pratt, M. E. (2014). Predictors of early growth in academic achievement: The Head-Toes-Knees-Shoulders task. Frontiers in Psychology, 5, 599.

McHale, J. P., Dinh, K. T., \& Rao, N. (2014). Understanding coparenting and family systems among East and Southeast Asian-heritage families. In H. Selin (Ed.), Parenting across cultures (7) (pp. 163-173). Dordrecht: Springer Netherlands.

McHale, J. P., Kuersten-Hogan, R., \& Rao, N. (2004). Growing points for coparenting theory and research. Journal of Adult Development, 11(3), 221-234.

McHale, J. P., Rao, N., \& Krasnow, A. D. (2000). Constructing family climates: Chinese mothers' reports of their co-parenting behaviour and preschoolers' adaptation. International Journal of Behavioral Development, 24(1), 111-118.

Morrill, M. I., Hines, D. A., Mahmood, S., \& Córdova, J. V. (2010). Pathways between marriage and parenting for wives and husbands: The role of coparenting. Family Process, 49(1), 59-73.

Muthén, L. K., \& Muthén, B. O. (1998-2012). Mplus user's guide (7th ed.). Los Angeles: Muthén \& Muthén.

O'Leary, S. G., \& Vidair, H. B. (2005). Marital adjustment, child-rearing disagreements, and overreactive parenting: Predicting child behavior problems. Journal of Family Psychology, 19, 208-216.

Parkes, A., Green, M., \& Mitchell, K. (2019). Coparenting and parenting pathways from the couple relationship to children's behavior problems. Journal of Family Psychology, 33(2), 215-225. 
Passolunghi, M. C., Mammarella, I. C., \& Altoè, G. (2008). Cognitive abilities as precursors of the early acquisition of mathematical skills during first through second grades. Developmental Neuropsychology, 33(3), 229-250.

Pedro, M. F., Ribeiro, T., \& Shelton, K. H. (2012). Marital satisfaction and partners' parenting practices: The mediating role of coparenting behavior. Journal of Family Psychology, 26(4), 509-522.

Rao, N., Sun, J., Ng, M., Becher, Y., Lee, D., Ip, P., \& Bacon-Shone, J. (2014). Validation, finalization and adoption of the East Asia-Pacific Early Child Development Scales (EAP-ECDS). UNICEF. Retrieved from: http://www.arnec. net/wp-content/uploads/2015/07/EAP-ECDS-Final-Report1.pdf

Ren, L., \& Edwards, C. P. (2016). Contemporary Chinese parents' socialization priorities for preschoolers: A mixed methods study. Early Child Development and Care, 186(11), 1779-1791.

Ren, L., Zhang, X., Yang, W., \& Song, Z. (2018). Relations among parenting, child behavioral regulation and early competencies: A study on Chinese preschoolers. Journal of Child and Family Studies, 27(2), 639-652.

Rogoff, B. (2003). The cultural nature of human development. New York: Oxford University Press.

Sektnan, M., McClelland, M. M., Acock, A., \& Morrison, F. J. (2010). Relations between early family risk, children's behavioral regulation, and academic achievement. Early Childhood Research Quarterly, 25(4), 464-479.

Shrout, P. E., \& Bolger, N. (2002). Mediation in experimental and nonexperimental studies: New procedures and recommendations. Psychological Methods, $7(4), 422-445$.

Shu, H., Peng, H., \& McBride-Chang, C. (2008). Phonological awareness in young Chinese children. Developmental Science, 11, 171-181.

Stright, A. D., \& Bales, S. S. (2003). Coparenting quality: Contributions of child and parent characteristics. Family Relations, 52(3), 232-240.

Teubert, D., \& Pinquart, M. (2010). The association between coparenting and child adjustment: A meta-analysis. Parenting: Science and Practice, 10(4), 286-307.

Woodcock, R. W., McGrew, K. S., \& Mather, N. (2001). Woodcock-Johnson III Tests of Achievement (3rd ed.). Itasca, IL: Riverside.

Wu, P., Robinson, C. C., Yang, C., Hart, C. H., Olsen, S. F., Porter, C. L., . . \& Wu, $X$. (2002). Similarities and differences in mothers' parenting of preschoolers in China and the United States. International Journal of Behavioral Development, 26(6), 481-491.

Zhang, X., Hu, B. Y., Ren, L., \& Fan, X. (2017). Pathways to reading, mathematics, and science: Examining domain-general correlates in young Chinese children. Contemporary Educational Psychology, 51, 366-377. 